\title{
MiR1511 co-regulates with miR1511* to cleave the GmRPLAa gene in soybean
}

\author{
LUO ZhongQin, JIN LongGuo \& QIU LiJuan* \\ The National Key Facility for Crop Gene Resources and Genetic Improvement (NFCRI), Institute of Crop Science, Chinese Academy of \\ Agricultural Sciences, Beijing 100081, China
}

Received November 28, 2011; accepted April 1, 2012; published online May 23, 2012

\begin{abstract}
MicroRNA1511 (miR1511) is a small RNA with unknown function identified in several plants by deep sequencing. In this study, we showed that this small RNA is an authentic miRNA by analyzing the structure of the precursor stem-loop containing the newly identified miR1511* sequence. We confirmed this result by Northern blotting analysis. We used 5'RACE to identify one of the target genes (GmRPL4a) cleaved by both miR1511 and miR1511*. The site cleaved by miR $1511^{*}$ was located in the first exon of GmRPL4a, and the site cleaved by miR1511 was located in the second exon. The expression level of miR1511/1511* was higher in leaves than in roots and stems. In contrast, the lowest level of GmRPLAa expression was in the leaves and the highest in the root. These results indicate that an miRNA can co-regulate with an miRNA* to cleave the same target gene in plants, and that the level of GmRPLAa mRNA is regulated by miR1511/1511*.
\end{abstract}

soybean, miR1511, miR1511*, GmRPL4a

Citation: $\quad$ Luo Z Q, Jin L G, Qiu L J. MiR1511 co-regulates with miR1511* to cleave the GmRPL4a gene in soybean. Chin Sci Bull, 2012, 57: 3804-3810, doi: $10.1007 / \mathrm{s} 11434-012-5197-9$

MicroRNAs (miRNAs) are widely found in animals and plants. They are expressed at high levels, and they have the characteristics of phylogenetic conservation and diversity [1-4]. Therefore, miRNAs have become a hotspot for biological research and many studies are now focusing on this topic. miRNAs are a family of single-stranded small RNAs that are 21-25 nucleotides (nt) in length. They can cleave or inhibit translation of a target mRNA via complementarity between the miRNA and its target mRNA [3,5,6]. The number of miRNAs in the miRBase database [7] has increased by approximately 100 times over the last decade, from 218 in release V1.0 (2002) to 21642 in release V18.0 (2011). At present, most studies on miRNAs focus on their identification and validation. A few studies have focused on how miRNAs regulate expression and other biological functions, using several conserved miRNAs in model organisms. For example, miR156 [8-10], miR159 [11], miR172 [12, $13]$, and miR396 [14,15] regulate the growth and develop-

*Corresponding author (email: qiu_lijuan@263.net) ment of leaves and flowers, while miR393 [16,17], miR398 [18,19], miR395 [20], and miR399 [21,22] play important roles in the responses of plants to environmental and nutrition stresses. However, the functions of numerous novel miRNAs have not yet been characterized. Soybean (Glycine $\max )$ is one of the most important oil, grain, and forage crops, but research on its miRNAs lags behind that on those in other model plants such as rice and Arabidopsis. To date, only a few soybean miRNAs have been analyzed in terms of their function [23-32].

miR1511 is a novel small RNA that was first identified in soybean [23], but has since been found in Phaseolus vulgaris [33], Medicago truncatula [34], and Vitis vinifera [35]. So far, there have been no experimental studies on miR1511. In this study, we verified the existence of miR1511 by sequencing and Northern blotting analyses. We found that miR1511 co-regulated with miR $1511^{*}$ to cleave and regulate the same gene, GmRPLAa. These results provide a theoretical foundation for the study of miR1511/1511* and their target genes. 


\section{Materials and methods}

\subsection{Plant materials}

We used the soybean (G. max) cultivar Zhongpin 95-5383, which was bred in our laboratory. Seeds were surface-sterilized in $8 \%$ Clorox for $4 \mathrm{~min}$ and then in $70 \%$ ethanol for $4 \mathrm{~min}$. The seeds were rinsed three times with sterile deionized water [23]. Plants were grown in an illuminated incubator at $25^{\circ} \mathrm{C}, 65 \%$ relative humidity under a 16-h light/8-h dark photoperiod with a light intensity of 10000 lx. The leaves, stems, and roots of 20-d-old seedlings were collected, immediately frozen in liquid nitrogen, and stored at $-80^{\circ} \mathrm{C}$ until use.

\subsection{Collection of bioinformatics data and analytical tools}

The soybean genome sequences were obtained from the Phytozome database (http://www.phytozome.net/). The analysis of the secondary structure of miRNA precursors was performed using the web-based software Mfold (http:// mfold.rna.albany.edu/?q=mfold/RNA-Folding-Form). Target genes of miRNA were predicted by psRNATarget (http://plantgrn.noble.org/psRNATarget/) using data from DFCI Soybean Gene Index Release 15.0 (http://compbio. dfci.harvard.edu/cgi-bin/tgi/gimain.pl?gudb=soybean) and soybean mRNA sequences obtained from the Phytozome database (ftp://ftp.jgi-psf.org/pub/JGI_data/phytozome/v6.0/ Gmax/assembly/) according to Fahlgren's methods [36]. We used the Primer Premier Version 5.00 software package (Premier Biosoft International) to design primers [37] and Multalin (http://multalin.toulouse.inra.fr/multalin/multalin. html) for sequence alignments.

\subsection{Small RNA extraction and enrichment}

We extracted total RNA from each sample using the RNAiso Plus kit (TaKaRa Biotechnology, Dalian, China) following the manufacturer's instructions and Accerbi's methods [38]. The method for small RNA enrichment was as follows [39]: $400 \mu \mathrm{L}(1-2 \mathrm{mg})$ total RNA was mixed with $50 \mu \mathrm{L}$ each of $50 \%$ PEG8000 and $5 \mathrm{~mol} / \mathrm{L}$ sodium chloride. The mixture was incubated on ice for $2 \mathrm{~h}$ and then centrifuged at $15000 \times g$ for $10 \mathrm{~min}$. A $1 / 10$ volume of $3 \mathrm{~mol} / \mathrm{L}$ sodium acetate ( $\mathrm{pH} 5.2$ ), two volumes of $95 \%$ ethanol, and $1 \mu \mathrm{L} 20 \mathrm{mg} / \mathrm{mL}$ glycogen (MBI Fermentas, Vilnius, Lithuania) were added to the supernatant and the mixture incubated at $-20^{\circ} \mathrm{C}$ for $2 \mathrm{~h}$ before sedimenting small RNAs at $15000 \times g$. The pellets were washed twice with $75 \%$ ethanol, dried briefly, and resuspended in $50 \%$ deionized formamide.

\subsection{Northern blotting analysis}

We conducted Northern blotting analysis as described elsewhere [40]. Briefly, $40 \mu \mathrm{g}$ enriched small RNAs was separated on a $15 \%$ polyacrylamide gel containing $8 \mathrm{~mol} / \mathrm{L}$ urea, then RNA was blotted onto positively charged nylon membranes (Amersham Life Science, Buckinghamshire, UK) using a semi-dry transfer cell (BioRad Laboratories, Richmond, CA, USA). After transfer, the membrane was crosslinked in an ultraviolet crosslinker (UVP, San Gabriel, CA, USA) in order of obverse, reverse, and obverse sides for $1 \mathrm{~min}$ each side. The membrane was baked at $80^{\circ} \mathrm{C}$ for at least $30 \mathrm{~min}$ and then prehybridized at $42^{\circ} \mathrm{C}$ in ULTRAhyb-Oligo buffer (Ambion, Austin, TX, USA). After $2 \mathrm{~h}$, the oligonucleotide probes 5' end-labeled with OptiKinase (USB Corp, Cleveland, OH, USA) were added and the membrane was left to hybridize overnight (14-24 h). The hybridized membrane was exposed to a storage phosphor screen (GE Healthcare, Milwaukee, WI, USA) and scanned using FX Pro Plus (BioRad Laboratories, Hercules, CA, USA).

\subsection{Validation of target genes by 5'RACE}

We carried out 5'RACE using the First-Choice RLM-RACE kit (Ambion Corp., Austin, TX, USA). The procedures were modified slightly, as follows [40]: the 5'RACE adapter was directly ligated to total RNA $(1 \mu \mathrm{g})$ without calf intestinal phosphatase (CIP) and tobacco acid pyrophosphatase (TAP) treatment. We used random decamers for cDNA synthesis with M-MLV reverse transcriptase. Touch-down PCR was performed with the nested primer specific to the predicted miRNA target gene and the nested primer corresponding to the $5^{\prime} \mathrm{RACE}$ adapter. The amplification conditions were as follows: $94^{\circ} \mathrm{C}$ for $4 \mathrm{~min}$; 12 cycles of $94^{\circ} \mathrm{C}$ for $30 \mathrm{~s}$, $64-53^{\circ} \mathrm{C}$ for $30 \mathrm{~s}, 72^{\circ} \mathrm{C}$ for $30 \mathrm{~s}\left(-1^{\circ} \mathrm{C} /\right.$ cycle $)$ and 30 cycles of $94^{\circ} \mathrm{C}$ for $30 \mathrm{~s}, 58^{\circ} \mathrm{C}$ for $30 \mathrm{~s}, 72^{\circ} \mathrm{C}$ for $30 \mathrm{~s}$; with final extension at $72^{\circ} \mathrm{C}$ for $8 \mathrm{~min}$. The two PCR amplifications were the same, but the template for the second PCR was $1 / 10$ of the products of the first PCR. The PCR products from the second PCR amplification were electrophoresed on a $1.2 \%$ agarose gel. The expected fragments were isolated using a DNA gel extraction kit (Axygen Biotechnology, Hangzhou, China) and then ligated into the pMD18-T vector (TaKaRa Biotechnology) at $16^{\circ} \mathrm{C}$ for $1 \mathrm{~h}$. Escherichia coli Top10 competent cells (Tiangen Biotech, Beijing, China) were transformed with the ligation products and spread onto LB agar plates containing $50 \mu \mathrm{g} / \mathrm{mL}$ ampicillin. The plates were incubated at $37^{\circ} \mathrm{C}$ for $12-16 \mathrm{~h}$. Randomly selected colonies were cultured in liquid LB medium with 50 $\mu \mathrm{g} / \mathrm{mL}$ ampicillin at $37^{\circ} \mathrm{C}$ on an oscillator for $6 \mathrm{~h}$. Positive recombinant clones were screened by colony PCR. PCR products containing the expected inserts were sent to GENEWIZ (Beijing, China) for sequencing using M13 forward and reverse primers.

\subsection{Real-time PCR analysis of target gene}

cDNA was synthesized from $1 \mu \mathrm{g}$ RNA using the Reverse 
Transcription System (Promega Ltd., Southampton, UK) following the manufacturer's instructions. The transcript levels in various tissues were determined using the 7300 real-time PCR system (Applied Biosystems, Foster City, CA, USA) using FastStart Universal SYBR Green Master Mix (Roche Diagnostics GmbH, Mannheim, Germany). Each well contained $10 \mu \mathrm{L} 2 \times \mathrm{ROX}, 0.5 \mu \mathrm{L}$ forward primer $\left.(10 \mu \mathrm{mol} \mathrm{L})^{-1}\right), 0.5 \mu \mathrm{L}$ reverse primer $\left(10 \mu \mathrm{mol} \mathrm{L} \mathrm{L}^{-1}\right), 1 \mu \mathrm{L}$ $1 / 10$ diluted cDNA, and $8 \mu \mathrm{L}$ water. The PCR program was as follows: $95^{\circ} \mathrm{C}$ for $10 \mathrm{~min}$; followed by 40 cycles of $95^{\circ} \mathrm{C}$ for $15 \mathrm{~s}$ and $60^{\circ} \mathrm{C}$ for $30 \mathrm{~s}$. ACT11 was used as the reference gene [41].

\subsection{Probes and primers}

The common probes and primers were synthesized by Sangon Biotechnology Ltd. (Beijing, China). The LNA-modified probes were purchased from Exqion Inc. (Vedbaek, Denmark), and included the miR1511 probe (Nor_1511), 5'-CCATGGTATCAGAGCCTGGTT-3'; the U6 snRNA probe (Nor_U6), 5'-GACCATTTCTCGATTTGTGCGTGTC-3'; and the miR1511 ${ }^{*}$ LNA probe, $5^{\prime}-\mathrm{TG}^{+} \mathrm{AAGC}^{+}-$ $\mathrm{AGGA}^{+} \mathrm{CCTG}^{+} \mathrm{ATAC}^{+} \mathrm{CAC}-3^{\prime}$ (LNA_1511S) (the base before " + " was LNA-modified). Probes 5 ' end-labeled with $\left[\gamma-{ }^{32} \mathrm{P}\right]$ ATP (FuRui Biology Engineer Co. Ltd., Beijing, China) were used as hybridization probes. The adapters and primers for 5'RACE were as follows: 5'RACE adapter, 5'-GCUGAUGGCGAUGAAUGAACACUGCGUUUGCUGGCUUUGAUGAAA-3'; 5'RACE outer primer (5'OP), 5'-GCTGATGGCGATGAATGAACACTG-3'; 5'RACE inner primer (5'IP), 5'-GAACACTGCGTTTGCTGGCTTTGATG-3'; gene-specific primers Tg5580R1, 5'-GAATTTGCACTATAAAATCCGACAAAC-3'; Tg5580R2, 5'-CAAAGATATTTAGTTCTGATGGGCATAC-3' (where R1 is the outer primer and $\mathrm{R} 2$ is the inner primer). The primers for real-time PCR were designed from the sequence of the cleavage site of the miRNA target gene: qRTmiR1511S5580F, 5'-TGTGAAGAAGGCCACGCTGAAG-3'; qRTmiR1511S-5580R, 5'-CAGTCTTCCTCTTCTTGTCGAGC-3' (primer pair was in the first exon across the cleavage site of miR1511*); and qRTmiR1511-5580F, 5'-GCTTCTGCCATCAAGTCTGCTG-3'; qRTmiR1511-5580R, 5'-ACTGTGAAACACCCAGCCACTTAG-3' (primer pair was in the second exon across the cleavage site of miR1511). We used the following primer pair for amplification of the reference gene ACT11: ACT11F, 5'-ATCTTGACTGAGCGTGGTTATTCC-3'， ACT11R， 5'-GCTGGTCCCTGGCTGTCTCC-3'.

\section{Results}

\subsection{Structure and chromosomal location of pre-miR1511}

A total of 12 small RNA sequences located in the same region of chromosome 18 (21161219-21161347 bp, full length of $129 \mathrm{bp}$ ) were identified by high throughput sequencing of a small RNA library constructed from the soybean variety Zhongpin95-5383 (unpublished data). The predicted secondary structure of this sequence was a stem-loop structure. Among the 12 small RNAs, four were located on the $5^{\prime}$ arm of the stem-loop, six on the $3^{\prime}$ arm of the stem-loop, and two on the complementary strand. The sequence with the highest number of reads (371) was 21-nt long and was located on the $3^{\prime}$ arm of the stem-loop. This 21-nt sequence, which had only one more nucleotide (guanine) at the 5' end than gma-miR1511, was located in the same region of the chromosome as gma-miR1511 obtained from miRBase (http://www.mirbase.org/). Therefore, this 21-nt sequence was designated as miR1511. Another 21-nt sequence (41 reads) located on the $5^{\prime}$ arm of the stem-loop was nearly complementary to miR 1511 , and was designated as miR1511*. The whole 129-bp sequence was located in an intergenic region of chromosome 18 , and was designated as the miR1511 precursor pre-miR1511 (Figure 1) [2,42,43]. This sequence was located 10405 bp downstream of Glymal8g19410.1 and 12789 bp upstream of Glymalsg19420.1 (Figure 1(b)).

\subsection{Target gene cleavage site analysis of miR1511/1511*}

A total of 10 putative target genes of miR1511 were predicted, but 5'RACE analysis confirmed the cleavage site of only one gene, Glymalog05580. The results of 5'RACE showed that three specific products were obtained by removing a single primer-binding PCR product (Figure 2(a)). The sequences of two bands were the binding sites of miR1511* and miR1511. Sequence alignment showed that the cleavage site of miR $1511^{*}$ was located in the first exon of Glymalog 05580 and that of miR1511 was located in the second exon of Glymalog05580, indicating that miR1511 and miR $1511^{*}$ both had a binding site on this target gene for co-cleavage (Figure 2(b)). Furthermore, another specific band may reflect cleavage of Glymalog05580 by an unknown miRNA; therefore, Glymalog05580 may be the target gene of more than one miRNA. Glymalog05580 belongs to the $60 \mathrm{~S}$ ribosomal protein L4 family and is homologous to RPLAa in Arabidopsis (henceforth designated as GmRPL4a) (Figure 2(c)). There is another copy of GmRPL4a in the soybean genome, Glymal3g19930, which was designated as GmRPLAd because of its similarity to the $A r$ abidopsis RPLAd gene. The predicted amino acid sequences of GmRPLA a and GmRPLAd had greater than 50\% similarity to the $60 \mathrm{~S}$ ribosomal protein L4 in human and mice and greater than $80 \%$ similarity to the Arabidopsis RPL4a and RPL4d proteins (Figure 2(d)).

\subsection{Tissue specific expression analysis of miR1511/ miR1511*and their target gene}

To study the expression of miR1511/miR $1511^{*}$ in different 


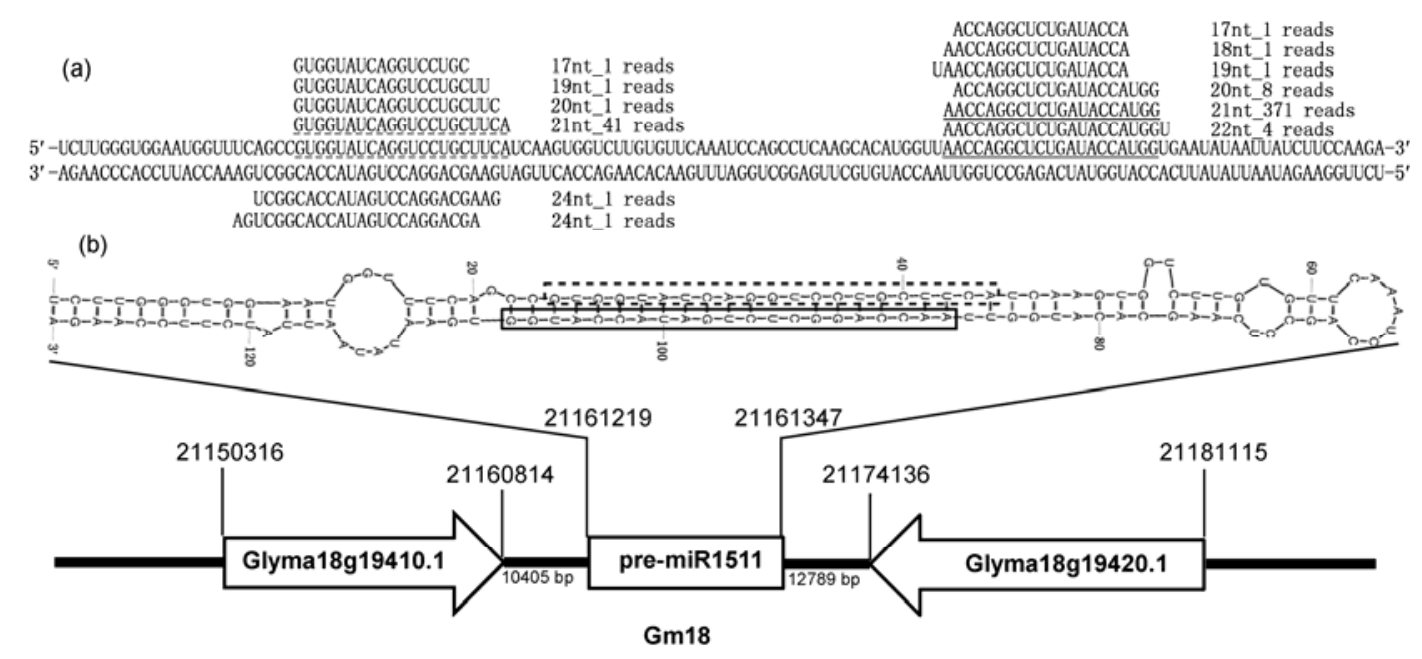

Figure 1 Sequence, stem-loop structure, and chromosome location of miR1511/miR1511*. (a) Length and read number distribution of pre-miRNA; (b) pre-miRNA stem-loop structure and genome location. Solid line indicates miR1511, dashed line indicates miR1511*.

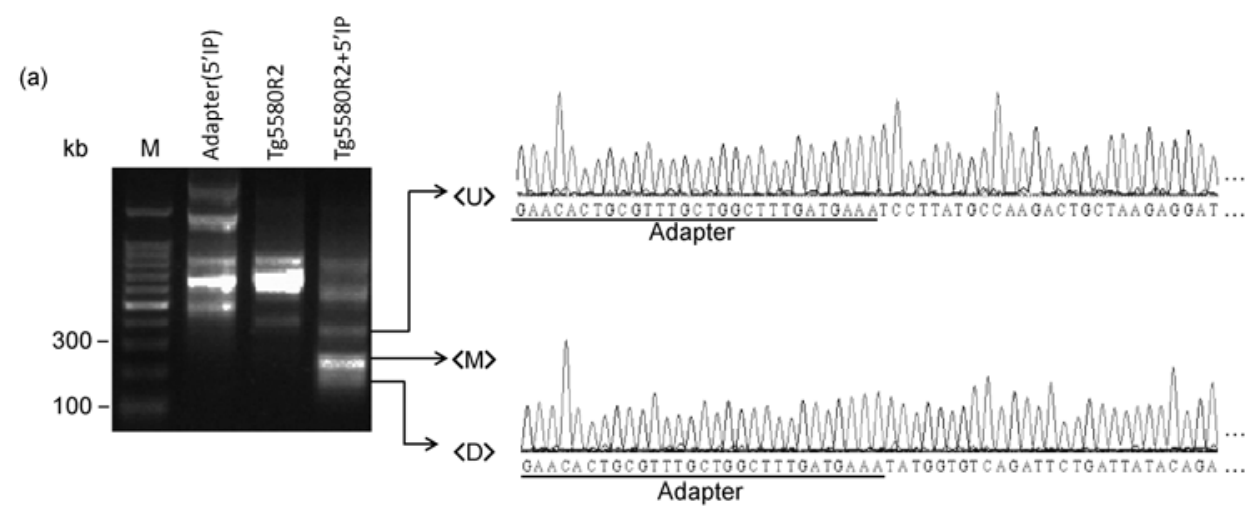

(b)



(c)

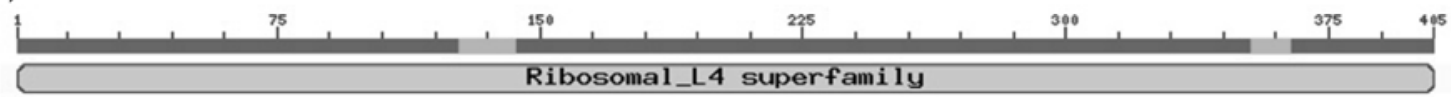

(d)

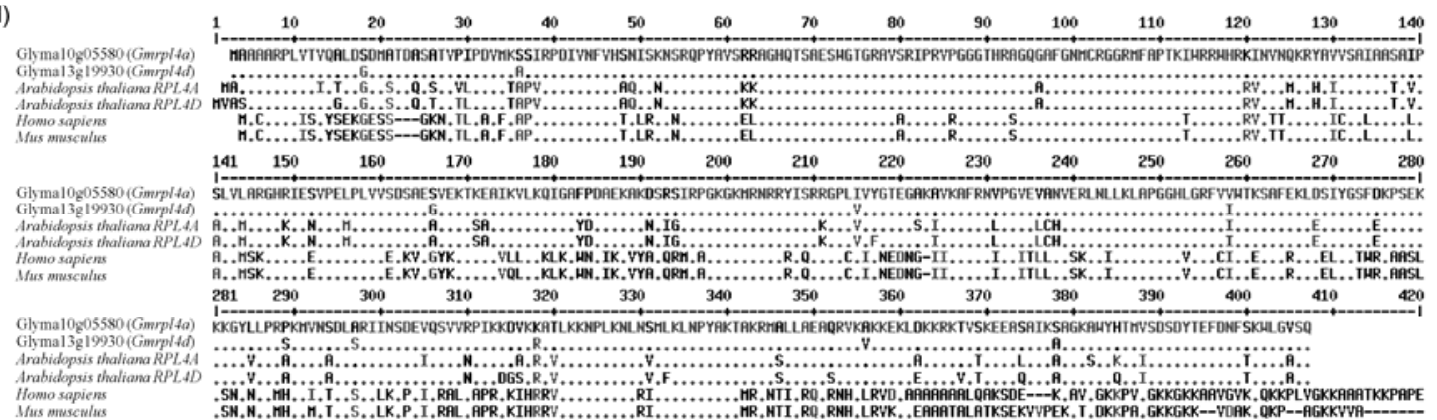

Figure 2 Target gene cleavage site analysis of miR1511/miR1511*. (a) 5'RACE and sequencing analysis; (b) schematic diagram of cleavage site; (c) predicted conserved region; (d) sequence alignment of RPL4 protein from soybean, Arabidopsis, human, and mice. M, 100 bp marker; $\langle\mathrm{U}\rangle,\langle\mathrm{M}\rangle$ and $\langle\mathrm{D}\rangle$, band number; "." indicates the same amino acid. 
tissues, we carried out Northern blotting analyses using RNA obtained from roots, leaves, and stems of Zhongpin95-5383 with miR1511/miR1511* specific probes and U6 snRNA as the internal reference. miR1511 was predominantly expressed in the leaves, with low to moderate expression in the roots and stems. The expression pattern of miR $1511^{*}$ was similar to that of miR1511 with weak signals in the leaves and stems. These results differ from those of a previous study in which miR1511 was expressed at its highest level in stems [28]. This difference might be because of differences in the variety and/or sampling period.

We designed two pairs of primers according to the sequence of the miR1511* and miR1511 cleavage sites in GmRPLA $a$ mRNA. These primers were used to analyze the expression pattern of GmRPLAa in roots, stems, and leaves by real-time PCR. The relative expression patterns obtained using these two pairs of primers were similar. The highest expression level of GmRPLAa was in roots (more than twice that in the leaves) and it was expressed at moderate levels in stems (1.6-1.8 times that in leaves) (Figure 3(b) and (c)). Therefore, the expression pattern of GmRPLAa was negatively correlated with that of miR1511/1511*, suggesting that the expression of GmRPLAa decreased with increasing expression of miR1511/1511*.

\section{Discussion}

\section{1 miR1511 is an authentic miRNA}

Previously, high-throughput sequencing analyses identified miR1511 in soybean [23], P. vulgaris [33], M. truncatula [34], and grape [35], and its tissue-specific expression had been detected by Northern blotting [28]. However, the complementary strand of miR1511 (miR1511*) had never been identified. Identification of the complementary strand is a requirement for the classification of a small RNA as an miRNA [5,44]. In this study, we identified miR $1511^{*}$ by high-throughput sequencing and Northern blotting. The stem-loop structure analysis of the precursor indicated that miR1511 and miR1511* originate from two arms of the stem-loop structure with a 2-nt overhang at the $3^{\prime}$ end and a 3-bp mismatch in the complementary region. This structure was consistent with the standards for miRNAs [5], proving the authenticity of miR1511.

\subsection{GmRPL4a was co-cleaved by miR1511 and miR1511*}

We verified the cleavage sites in the target gene of miR1511, GmRPLAa, by 5'RACE. These results were consistent with soybean miRNA degradome sequencing data reported previously [30], but the cleavage site was slightly different. miR $1511^{*}$, the complementary strand of miR1511, and its target gene were also identified by $5^{\prime} \mathrm{RACE}$, indicating that miR1511/miR1511* could co-regulate the same target gene (Figure 2(b)). GmRPLAa and GmRPLAd, which show high sequence similarity to each other $(90 \%)$, belong to the $60 \mathrm{~S}$ ribosomal protein L4 family and have the same binding site for miR1511/1511* (Figure 2). High-throughput sequencing results showed that miR1511 also cleaved GmRPLAd [30], but this may not be accurate because of the short sequence read. The cleavage of GmRPLAd was not verified by 5'RACE in this study, which might be the result of the low expression level of GmRPLAd in the tissue examined, or some other unknown regulatory mechanism. The expression of GmRPLAa was negatively correlated with that of miR $1511 / 1511^{*}$ in roots, stems, and leaves, indicating that they may be controlled via the same regulatory mechanism. However, the expression level of GmRPLAa could not reflect regulation of miR 1511 because of the possible influence of GmRPLAd and regulation of other miRNAs.

The basic function of ribosomal proteins, which are key components of the ribosomal subunit, is in ribosome assembly and protein synthesis. Many studies have shown that ribosomal proteins have various other ribosome-independent functions in plants and animals, playing roles in cell growth, differentiation, development, apoptosis, and regulation of stress responses [19-26]. Research on the mutants $r p l 5 a, r p l 5 b, r p l 24 b$, and $r p l 28 a$ indicated that the entire ribosomal large subunit was involved in establishing abaxialadaxial leaf polarity in Arabidopsis. The ribosome might be involved in the processing of one central network during the establishment of leaf polarity [25]. A study on mutants of 11 ribosomal proteins in Arabidopsis provided further evidence that the ribosome plays an important role in establishing leaf polarity. The rpl4d mutation did not affect cell proliferation but caused strong abaxialization of leaves in
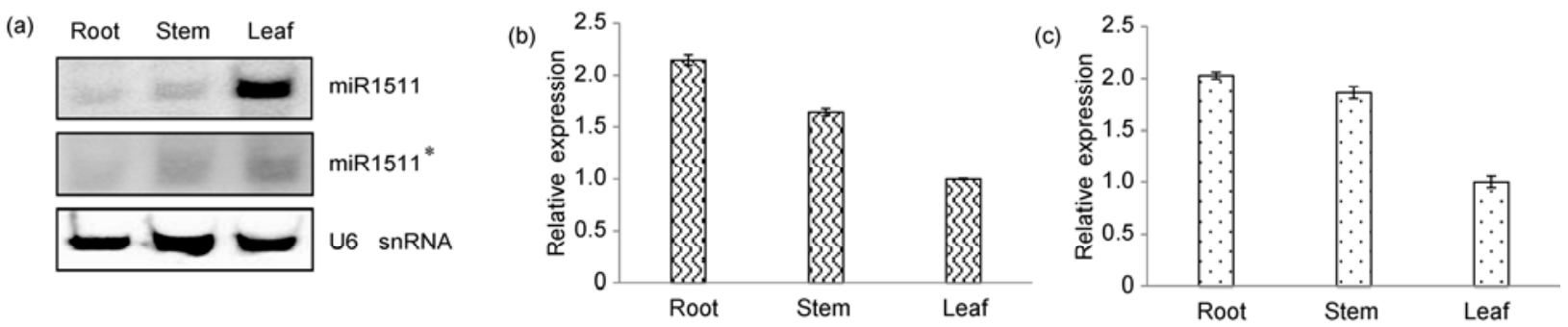

Figure 3 Expression of miR1511/miR $1511^{*}$ and target gene GmRPL4a in soybean roots, stems, and leaves. (a) Northern blotting of miR1511/miR1511* in different tissues; (b) and (c) real-time RT-PCR analysis of GmRPL4a in different tissues using primers designed from mR1511 cleavage site (b) and primers designed from $\mathrm{mR} 1511^{*}$ cleavage site $(\mathrm{c})$. 
the as 1 and as 2 backgrounds [26].

In this study, the deduced amino acid sequence of GmRPLAa showed high similarity (greater than 80\%) to RPL4A and RPL4D proteins in Arabidopsis (Figure 2(d)). Also, the highest level of miR1511/1511* expression was in the leaves (Figure 3(a)). Therefore, based on the study of $R P L$ genes in Arabidopsis, miR1511/1511* may play a role in regulating the development of soybean leaves. However, because the 5'RACE results on target cleavage suggested that GmRPLAa may be regulated by other miRNA(s) in soybean (Figure 2(a)), the contribution of miR1511/1511* to regulating soybean leaf development requires further study.

\subsection{Functions of miRNA*}

Generally, it is considered that miRNA*s integrate into the degradation pathway after the formation of mature miRNAs. However, in-depth studies of miRNAs [53] are providing more evidence that miRNA* ${ }^{*}$ save other functions in plants and animals. In animals, miR199a ${ }^{*}$ may play a role in inhibiting proliferation, movement, and invasiveness of cancer cells via negative regulation of mRNA and protein expression of its target gene MET (a proto-oncogene) and its downstream gene ERK2 (extracellular signal-regulated kinase 2) [27]. In addition, miR 199a* has a regulatory role in the formation of cartilage [55]. The expressions of miR-9 and miR-9* are significantly down-regulated in the cerebral cortex of patients with Huntington's disease, compared with that of healthy individuals. The target gene of miR-9 is REST and that of miR-9* is the REST co-repressor gene, CoREST, which form a double-negative feedback regulation loop [56].

In Arabidopsis, both miRNA* and miRNA could bind to different AGO proteins and form an RNA-induced silencing complex (RISC) because of the different 5 ' terminal nucleotide. This indicates that miRNA* $\mathrm{s}$ have the essential requirements for functionality [57]. The levels of miR399* increased during low phosphorus stress, and it was transported from shoots to roots, like miR399 [58]. A previous study also revealed that the expression levels of some miRNA*s were the same as, or higher than, those of miRNAs in the apical meristem or mature leaves of soybean. In addition, in situ hybridization analysis indicated that $\mathrm{miR} 166 \mathrm{a} / \mathrm{b}$ and $\mathrm{miR} 166 \mathrm{a} / \mathrm{b}{ }^{*}$ showed different expression patterns.

Some miRNA*s are more abundant than miRNAs in the mycorrhizal symbiosis in M. truncatula [28]. According to data analysis of degradome sequencing, 44 target genes may be cleaved by different miRNA* ${ }^{*}$. The latest research on miR393* revealed that its overexpression in Arabidopsis resulted in a phenotype like that of the memb12 mutant, the target gene mutant of miR393b*. miR393* and miR393 played the same role in plant resistance to exogenous bacterial invasion, but they combined with different AGO proteins to cleave a variety of target genes [60]. Although
miRNA* s can regulate target genes both independently or with a corresponding miRNA, our study is the first report that a single target gene can be cleaved by an miRNA and its complementary strand miRNA*.

This work was supported by the National Natural Science Foundation of China (30871621 and 30490251), the National Major Special Project on New Varieties Cultivation for Transgenic Organisms (2009ZX08009-088B), and the National High Technology Research and Development Program of China (2006AA10110)

1 Bartel D P. MicroRNAs: Genomics, biogenesis, mechanism, and function. Cell, 2004, 116: 281-297

2 Du T, Zamore P D. MicroPrimer: The biogenesis and function of microRNA. Development, 2005, 132: 4645-4652

3 Carrington J C, Ambros V. Role of microRNAs in plant and animal development. Science, 2003, 301: 336-338

4 Chen X. Small RNAs and their roles in plant development. Annu Rev Cell Dev Biol, 2009, 25: 21-44

5 Meyers B C, Axtell M J, Bartel B, et al. Criteria for annotation of plant microRNAs. Plant Cell, 2008, 20: 3186-3190

6 Ambros V. The functions of animal microRNAs. Nature, 2004, 431: 350-355

7 Kozomara A, Griffiths-Jones S. MiRBase: Integrating microRNA annotation and deep-sequencing data. Nucleic Acids Res, 2011, 39(Database issue): D152-D157

8 Yang L, Conway S R, Poethig R S. Vegetative phase change is mediated by a leaf-derived signal that represses the transcription of miR156. Development, 2011, 138: 245-249

9 Jiao Y, Wang Y, Xue D, et al. Regulation of OSSPL14 by OsmiR156 defines ideal plant architecture in rice. Nat Genet, 2010, 42: 541-544

10 Wang J W, Czech B, Weigel D. MiR156-regulated SPL transcription factors define an endogenous flowering pathway in Arabidopsis thaliana. Cell, 2009, 138: 738-749

11 Palatnik J F, Allen E, Wu X, et al. Control of leaf morphogenesis by microRNAs. Nature, 2003, 425: 257-263

12 Chen X. A microRNA as a translational repressor of APETALA2 in Arabidopsis flower development. Science, 2004, 303: 2022-2025

13 Grigorova B, Mara C, Hollender C, et al. LEUNIG and SEUSS co-repressors regulate miR172 expression in Arabidopsis flowers. Development, 2011, 138: 2451-2456

14 Rodriguez R E, Mecchia M A, Debernardi J M, et al. Control of cell proliferation in Arabidopsis thaliana by microRNA miR396. Development, 2010, 137: 103-112

15 Liu D, Song Y, Chen Z, et al. Ectopic expression of miR396 suppresses GRF target gene expression and alters leaf growth in Arabidopsis. Physiol Plant, 2009, 136: 223-236

16 Feng X M, Qiao Y, Wang S S, et al. Overexpression of Arabidopsis AtmiR393a gene alters the sensitivity to auxin in tomato. Sci Hortic, 2010, 124: 165-169

17 Navarro L, Jay F, Nomura K, et al. Suppression of the microRNA pathway by bacterial effector proteins. Science, 2008, 321: 964-967

18 Trindade I, Capitão C, Dalmay T, et al. miR398 and miR408 are up-regulated in response to water deficit in Medicago truncatula. Planta, 2010, 231: 705-716

19 Sunkar R, Kapoor A, Zhu J K. Posttranscriptional induction of two $\mathrm{Cu} / \mathrm{Zn}$ superoxide dismutase genes in Arabidopsis is mediated by downregulation of miR398 and important for oxidative stress tolerance. Plant Cell, 2006, 18: 2051-2065

20 Kawashima C G, Yoshimoto N, Maruyama-Nakashita A, et al. Sulphur starvation induces the expression of microRNA-395 and one of its target genes but in different cell types. Plant J, 2009, 57: 313-321

21 Bari R, Datt Pant B, Stitt M, et al. PHO2, microRNA399, and PHR1 define a phosphate-signaling pathway in plants. Plant Physiol, 2006, 141: 988-999

22 Aung K, Lin S I, Wu C C, et al. pho2, a phosphate overaccumulator, 
is caused by a nonsense mutation in a microRNA399 target gene. Plant Physiol, 2006, 141: 1000-1011

23 Subramanian S, Fu Y, Sunkar R, et al. Novel and nodulation-regulated microRNAs in soybean roots. BMC Genomics, 2008, 9: 160

24 Chen R, Hu Z, Zhang H. Identification of microRNAs in wild soybean (Glycine soja). J Integr Plant Biol, 2009, 51: 1071-1079

25 Wang Y, Li P, Cao X, et al. Identification and expression analysis of miRNAs from nitrogen-fixing soybean nodules. Biochem Biophys Res Commun, 2009, 378: 799-803

26 Joshi T, Yan Z, Libault M, et al. Prediction of novel miRNAs and associated target genes in Glycine max. BMC Bioinformatics, 2010, 11(Suppl 1): S14

27 Kulcheski F R, Marcelino-Guimaraes F C, Nepomuceno A L, et al. The use of microRNAs as reference genes for quantitative polymerase chain reaction in soybean. Anal Biochem, 2010, 406: 185-192

28 Li H, Deng Y, Wu T, et al. Misexpression of miR482, miR1512, and miR1515 increases soybean nodulation. Plant Physiol, 2010, 153: 1759-1770

29 Zeng H Q, Zhu Y Y, Huang S Q, et al. Analysis of phosphorus-deficient responsive miRNAs and cis-elements from soybean (Glycine max L.). J Plant Physiol, 2010, 167: 1289-1297

30 Song Q X, Liu Y F, Hu X Y, et al. Identification of miRNAs and their target genes in developing soybean seeds by deep sequencing. BMC Plant Biol, 2011, 11: 5

31 Wong C E, Zhao Y T, Wang X J, et al. MicroRNAs in the shoot apical meristem of soybean. J Exp Bot, 2011, 62: 2495-2506

32 Kulcheski F R, de Oliveira L F, Molina L G, et al. Identification of novel soybean microRNAs involved in abiotic and biotic stresses. BMC Genomics, 2011, 12: 307

33 Arenas-Huertero C, Pérez B, Rabanal F, et al. Conserved and novel miRNAs in the legume Phaseolus vulgaris in response to stress. Plant Mol Biol, 2009, 70: 385-401

34 Lelandais-Briere C, Naya L, Sallet E, et al. Genome-wide Medicago truncatula small RNA analysis revealed novel microRNAs and isoforms differentially regulated in roots and nodules. Plant Cell, 2009, 21: 2780-2796

35 Pantaleo V, Szittya G, Moxon S, et al. Identification of grapevine microRNAs and their targets using high-throughput sequencing and degradome analysis. Plant J, 2010, 162: 960-976

36 Fahlgren N, Carrington J C. miRNA target prediction in plants. Methods Mol Biol, 2010, 592: 51-57

37 Lalitha S. Primer Premier 5. Biotech Softw Internet Rep, 2000, 1: 270-272

38 Accerbi M, Schmidt S A, De Paoli E, et al. Methods for isolation of total RNA to recover miRNAs and other small RNAs from diverse species. Methods Mol Biol, 2010, 592: 31-50

39 Park W, Li J, Song R, et al. CARPEL FACTORY, a dicer homolog, and HEN1, a novel protein, act in microRNA metabolism in Arabidopsis thaliana. Curr Biol, 2002, 12: 1484-1495

40 Jeong D H, German M A, Rymarquis L A, et al. Abiotic stress-associated miRNAs: Detection and functional analysis. Methods Mol Biol, 2010, 592: 203-230

$41 \mathrm{Hu}$ R, Fan C, Li H, et al. Evaluation of putative reference genes for gene expression normalization in soybean by quantitative real-time RT-PCR. BMC Mol Biol, 2009, 10: 93

42 Li T, Li H, Zhang Y X, et al. Identification and analysis of seven
$\mathrm{H}_{2} \mathrm{O}_{2}$-responsive miRNAs and 32 new miRNAs in the seedlings of rice (Oryza sativa L. ssp. indica). Nucleic Acids Res, 2010, 39: 2821-2833

43 Berezikov E, Robine N, Samsonova A, et al. Deep annotation of Drosophila melanogaster microRNAs yields insights into their processing, modification, and emergence. Genome Res, 2011, 21: 203-215

44 Chen X. MicroRNA metabolism in plants. Curr Top Microbial Immunol, 2008, 320: 117-136

45 Warner J R, McIntosh K B. How common are extraribosomal functions of ribosomal proteins? Mol Cell, 2009, 34: 3-11

$46 \mathrm{Xu} \mathrm{R}$, Deng K, Zhu Y, et al. A large-scale functional approach to uncover human genes and pathways in Drosophila. Cell Res, 2008, 18: 1114-1127

47 Lohrum M A E, Ludwig R L, Kubbutat M H G, et al. Regulation of HDM2 activity by the ribosomal protein L11. Cancer Cell, 2003, 3: $577-587$

48 Kim K Y, Park S W, Chung Y S, et al. Molecular cloning of lowtemperature-inducible ribosomal proteins from soybean. J Exp Bot, 2004, 55: 1153-1155

49 Singh K, Paul A, Kumar S, et al. Cloning and differential expression of QM like protein homologue from tea [Camellia sinensis (L.) O. Kuntze]. Mol Biol Rep, 2009, 36: 921-927

50 Wool I G. Extraribosomal functions of ribosomal proteins. Trends Biochem Sci, 1996, 21: 164-165

51 Yao Y, Ling Q, Wang $\mathrm{H}$, et al. Ribosomal proteins promote leaf adaxial identity. Development, 2008, 135: 1325-1334

52 Horiguchi G, Mollá-Morales A, Pérez-Pérez J M, et al. Differential contributions of ribosomal protein genes to Arabidopsis thaliana leaf development. Plant J, 2011, 65: 724-736

53 Okamura K, Phillips M D, Tyler D M, et al. The regulatory activity of microRNA* species has substantial influence on microRNA and 3'UTR evolution. Nat Struct Mol Biol, 2008, 15: 354-363

$54 \mathrm{Kim}$ S, Lee U J, Kim M N, et al. MicroRNA miR-199a* regulates the $M E T$ proto-oncogene and the downstream extracellular signal-regulated kinase 2 (ERK2). J Biol Chem, 2008, 283: 18158-18166

55 Lin E A, Kong L, Bai X H, et al. miR-199a*, a bone morphogenic protein 2-responsive microRNA, regulates chondrogenesis via direct targeting to Smad1. J Biol Chem, 2009, 284: 11326-11335

56 Packer A N, Xing Y, Harper S Q, et al. The bifunctional microRNA miR-9/miR-9* regulates REST and CoREST and is downregulated in Huntington's disease. J Neurosci, 2008, 28: 14341-14346

57 Mi S, Cai T, Hu Y, et al. Sorting of small RNAs into Arabidopsis Argonaute complexes is directed by the $5^{\prime}$ terminal nucleotide. Cell, 2008, 133: 116-127

58 Hsieh L C, Lin S I, Shih A C, et al. Uncovering small RNA-mediated responses to phosphate deficiency in Arabidopsis by deep sequencing. Plant Physiol, 2009, 151: 2120-2132

59 Devers E A, Branscheid A, May P, et al. Stars and symbiosis: microRNA- and microRNA*-mediated transcript cleavage involved in arbuscular mycorrhizal symbiosis. Plant Physiol, 2011, 156: 19902010

60 Zhang X M, Zhao H W, Gao S, et al. Arabidopsis Argonaute 2 regulates innate immunity via miRNA393"-mediated silencing of a Golgi-localized SNARE gene, MEMB12. Mol Cell, 2011, 42: 356366

Open Access This article is distributed under the terms of the Creative Commons Attribution License which permits any use, distribution, and reproduction in any medium, provided the original author(s) and source are credited. 